\title{
Methylation of MMP2, TIMP2, MMP9 and TIMP1 in abdominal aortic aneurysm
}

\author{
Skorvanova $\mathrm{M}^{1}$, Matakova $\mathrm{T}^{1,2}$, Skerenova $\mathrm{M}^{2}$, Sarlinova $\mathrm{M}^{2}$, Drobkova $\mathrm{H}^{2}$, Petras $\mathrm{M}^{2}$, \\ Janickova $\mathrm{M}^{3}$, Halasa $\mathrm{M}^{4}$, Repiska $\mathrm{V}^{5}$, Halasova $\mathrm{E}^{2,6}$ \\ Department of Medical Biochemistry, Comenius University in Bratislava, Jessenius Faculty of Medicine, Martin, \\ Slovakia. erika.halasova@uniba.sk
}

\begin{abstract}
OBJECTIVES: Abdominal aortic aneurysm (AAA) and its complications are among the most serious cardiovascular diseases and its occurrence has risen sharply in recent years. The aim of this pilot study is to explore the relationship between the methylation of matrix metalloproteinases and tissue inhibitors of the metalloproteinases genes' promoter region, and abdominal aortic aneurysm (AAA) through the detection of the methylation status of MMP2, TIMP2, TIMP1, and MMP9 genes in peripheral blood.

METHODS: The study included 43 males with verified AAA (case group) and 34 healthy males (control group). The methylation status of the genes' promoter region was detected by methylation-specific polymerase chain reaction (MS-PCR).

RESULTS: In adominal aortic aneurysm patients, the methylation ratio of MMP2 gene was positive in $9.3 \%$ (4 cases), $2.3 \%$ (1 case) had methylated TIMP2 gene, $7.0 \%$ (3 cases) had methylated TIMP1 gene, while the methylation ratio of MMP9 gene was positive in $93.0 \%$ (40 cases). In the control group, MMP2 gene was found to be methylated in $5.9 \%$ ( 2 cases), $5.9 \%$ of cases had methylated TIMP2 and TIMP1 genes (2 cases), and MMP9 gene was found to be methylated in $91.2 \%$ (31 cases).

CONCLUSION: In our pilot study, we found no association between DNA methylation of gelatinases and their tissue inhibitors, and the development of an abdominal aortic aneurysm (Tab. 2, Fig. 1, Ref. 27). Text in PDF www.elis.sk

KEY WORDS: abdominal aortic aneurysm, matrix metalloproteinase, DNA methylation, methylation status.
\end{abstract}

\section{Introduction}

Aneurysm is an extension of an artery to approximately 1.5 times its usual diameter at a particular location. It occurs at a site where the aortic wall is weakened or has an abnormal structure

${ }^{1}$ Department of Medical Biochemistry, Comenius University in Bratislava, Jessenius Faculty of Medicine, Martin, Slovakia, ${ }^{2}$ Biomedical Center Martin, Comenius University in Bratislava, Jessenius Faculty of Medicine, Martin, Slovakia, ${ }^{3}$ Clinic of Stomatology and Maxillofacial Surgery, Comenius University in Bratislava, Jessenius Faculty of Medicine in Martin and University Hospital Martin, Martin, Slovakia, ${ }^{4} \mathrm{Clinic}$ of Surgery and Transplant Center, Comenius University in Bratislava, Jessenius Faculty of Medicine in Martin and University Hospital Martin, Martin, Slovakia, ${ }^{5}$ Department of Medical Biology, Genetics and Clinical Genetics, Comenius University in Bratislava, Faculty of Medicine, Bratislava, Slovakia, and ${ }^{6}$ Department of Medical Biology, Comenius University in Bratislava, Jessenius Faculty of Medicine, Martin, Slovakia

Address for correspondence: E. Halasova, Prof MD, PhD, Comenius University in Bratislava, Jessenius Faculty of Medicine, Biomedical Center Martin, Mala Hora 11161/4D, SK-036 01 Martin, Slovakia.

Acknowledgements: This work was supported by the Agency of Ministry of Education, Science, Research and Sport of the Slovak Republic under grant APVV-15-0181. This work was also supported by the project "Competence Center for Research and Development in the Field of Diagnostics and Therapy of Oncological Diseases (ITMS code: 26220220153).
(1). The inferiority of the vascular wall can be determined by genetic predisposition, as well as acquired as a result of inflammation of the vascular wall or atherosclerosis (2). Males are more prone to develop AAA, but environmental and lifestyle choices such as diet that leads to obesity, or smoking can trigger the disease. Other conditions include arterial hypertension, peripheral, arterial disease, coronary heart disease or hyperlipidaemia (3). The development of abdominal aortic aneurysm (AAA) is a consequence of complex genetic, environmental, biochemical and mechanical (hemodynamic) effects. The development of aneurysms is determined by various factors, and the search of genes responsible for the hereditary component of aneurysms has been associated with its aetiology, including increased neoangiogenesis (4), excessive degradation of extracellular matrix (5) and loss of extracellular protein (6), increased oxidative stress (7), chronic inflammation $(8,9)$ and changes in myosin structure in smooth muscle cells (10). Bryce et al (2015) identify this diagnosis as the third most common cause of sudden deaths in people aged 60 years or older in Europe. Metalloproteinases (MMPs) forming a large family of $\mathrm{Ca} / \mathrm{Zn}$-dependent endoproteinases are the most closely observed group of proteolytic enzymes in association with aneurysms. Various factors play an important role in MMP activation, such as cytokines released by inflammatory cells, other MMPs, free radicals, elastin degradation products, various microorganisms as 


\section{$717-721$}

well as mechanical damage $(11,12)$. Increased MMP production and activation is a feature of AAA. MMP2 and MMP9 elastases are important in the aetiology of AAA for their ability to cleave substrates such as elastin and collagen. A complex physiological process that involves the destruction of the aortic connective tissue results in the development of AAA (3). The presence of activated MMP2 and MMP9 contributes to the degradation of vascular ECM and development of AAA (12). The high concentration of MMPs in the aortic wall is caused not only by their increased production but also due to the deficiency of factors that prevent their action and have an inhibitory effect on MMPs (so-called tissue metalloproteinase inhibitors (TIMPs)). Disruption of the expression of matrix metalloproteinases and tissue metalloproteinase inhibitors (TIMP) involved in ECM degradation during inflammatory processes in the early and late stages of the disease plays a key role in the development of aneurysm (13). In normal tissue, MMPs are only expressed at low levels. Increased secretion and activation of MMP occurs only when tissue remodelling and various physiological and pathological processes are required (14). Under normal physiological conditions, MMP activity is strictly regulated at the level of transcription, activation of pro-MMP, as well as by inhibition of endogenous inhibitors - TIMP. Changes in the regulation of MMP activity may lead to development of cancer, fibrosis, arthritis, atherosclerosis, and other conditions $(15,16)$. DNA methylation may be a central mediator in AAA pathology. Changes in DNA methylation in genes directing ECM proteolysis regulatory cycles may specifically affect the phenotype of ECM structure and function (16), while changes in DNA methylation have been shown to affect the expression of various genes involved in the degradation of apoptosis of smooth muscle cells, vascular cell system (VSMC), inflammation and extracellular matrix (ECM) by imbalance in matrix metalloproteinases (MMPs) and tissue inhibitors of metalloproteinases (TIMPs) $(17,18)$. Transcription, expression and relationship with the methylation status of the promoter in normal and disease stages are actively investigated in many chronic inflammatory diseases. The results of such analyses may reveal new knowledge about the pathogenesis of AAA $(19,20)$. The main objective of this pilot study conducted on Slovakian patients was to determine the role of promoter methylation status of genes MMP2, TIMP2, MMP9 and TIMP1 in the development of AAA.

\section{Materials and methods}

\section{Ethics committee approval}

This study was approved by the Ethical Committee of the Jessenius Faculty of Medicine in Martin, Comenius University, Bratislava, Slovakia (December 13, 2017) and was conducted in compliance with the guidelines laid down in the Declaration of Helsinki 1964. Written informed consents were obtained from all subjects involved in the study.

\section{Study population}

The promoter methylation status of MMP2, TIMP2, MMP9 and TIMP1 was analysed in two groups. The present study included 43 males (mean age $=71.35 \pm 9.45$ years) with sonographically verified diagnosis of abdominal aortic aneurysm (AAA) with or without rupture, while each of the 43 AAA patients was the first person in their family (proband) to come to our attention. The control group was assembled from 34 healthy males (mean age $=60.0$ \pm 11.42 years). The selected group of healthy males were confirmed to be without any medical history of aneurysm or other vascular disorders. All subjects were Caucasians of European origin.

\section{DNA extraction and modification}

Venous blood $(5 \mathrm{ml})$ was taken into K2EDTA tubes from all males in the study and control groups. The isolation of genomic DNA from whole-blood samples was carried out using Wizard Genomic DNA Purification kit (Promega, Madison, WI, USA). Genomic DNA samples were stored at $-20{ }^{\circ} \mathrm{C}$ until epigenetic analysis. The methylation status of the MMP2, TIMP2, MMP9 and TIMP1 genes' promoters was determined by bisulphite treatment of DNA. $500 \mathrm{ng}$ of DNA in $50 \mu \mathrm{l}$ was used for bisulphite modification, which was performed using innuCONVERT Bisulfite All-In-One Kit (Annalytik Jena AG, Germany), while strictly following the instructions provided with the kit. The unmethylated cytosine $(\mathrm{C})$ in the sequence was transformed into uracil (U). Bisulphite-treated DNA was stored at $-80{ }^{\circ} \mathrm{C}$ until subjected to methylation-specific polymerase reaction (MS-PCR).

\section{Methylation-specific PCR (MS-PCR)}

The methylation status of MMP2, TIMP2, MMP9 and TIMP1 genes in their promoters' region was determined by MS-PCR. According to the whole genomic sequence and sequence of the promoter region of observed genes, the CpG islands of this gene's promoter were searched using the DNA methylation research tool software "MethPrimer", and the primers were designed afterwards. Sequences of primers are presented in Table 1.

MS-PCR was performed in $20 \mu \mathrm{l}$ master mix consisting of 0.8 $\mu 1$ of bisulfite-treated DNA, $4 \mu 1$ 5x HOT FIREPol Blend Master Mix RTL with $7.5 \mathrm{mM} \mathrm{MgCl}$ (Solis Biodyne), $0.12 \mu \mathrm{l}$ of each primer $\left(25 \mu \mathrm{mol} . \mu \mathrm{l}^{-1}\right)$ and $15.6 \mu \mathrm{l}$ of DNase-free water.

CpG Methylated Human Genomic DNA (Thermo Fisher Scientific) was used as a positive methylation control, while CpG Unmethylated Human Genomic DNA (Thermo Fisher Scientific) was used as an unmethylated control. Thermal cycling parameters were as follows: pre-denaturation at $95^{\circ} \mathrm{C}$ for 5 minutes and 35 cycles consisting of $20-35 \mathrm{~s}$ of denaturation at $95{ }^{\circ} \mathrm{C}$ (depending on the primers used), 20-35 s of hybridization at different annealing temperatures (Tab. 1), and $20-35 \mathrm{~s}$ of elongation at $72{ }^{\circ} \mathrm{C}$, followed by $5-10$ minutes of elongation at $72{ }^{\circ} \mathrm{C}$. PCR products were analysed on $2 \%$ agarose gel with ethidium bromide (Calbiochem) and visualized under ultraviolet light. The presence of PCR products of the correct molecular weight indicated the presence of either methylated or unmethylated alleles. The status was evaluated as methylated when the resulting band of expected length appeared in samples that were amplified with methylated primers. When the resulting expected band appeared in samples that were amplified with unmethylated primers, the status was evaluated as unmethylated. The experiment was repeated three times with no differences observed. Examples of examined gene are shown in Figure 1. 
Tab. 1. Specific condition for evaluation of methylation status in promoter region of MMP2, TIMP2, TIMP1, and MMP9 genes.

\begin{tabular}{|c|c|c|c|c|}
\hline Gene & Forward primer 5'-3' & Reverse primer 5'-3' & $\begin{array}{l}\text { Annealing } \\
\text { temperature }\end{array}$ & $\begin{array}{l}\text { Product } \\
\text { (bp) }\end{array}$ \\
\hline$\overline{M M P 2 \mathrm{M}}$ & AGGGATTGTTAGGATTTGCG & CTCGATAACCTAAAATTTACCCGA & $64{ }^{\circ} \mathrm{C}$ & $100 \mathrm{bp}$ \\
\hline MMP2 U & AGGGATTGTTAGGATTTGTGG & 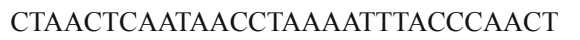 & $64{ }^{\circ} \mathrm{C}$ & $104 \mathrm{bp}$ \\
\hline TIMP2 M & GTTGAGTTAGGGATTTCGGG & GCGCTTTTATTATACCCGACC & $58^{\circ} \mathrm{C}$ & $153 \mathrm{bp}$ \\
\hline TIMP2 U & GTTGAGTTAGGGATTTTGGG & САСАСТTТТАТТАТАСССААССТААСАС & $63^{\circ} \mathrm{C}$ & $154 \mathrm{bp}$ \\
\hline TIMP1 M & AGATTTTAGGGGATTGGGTC & ATCCACGCTAAAAACGAAAA & $55^{\circ} \mathrm{C}$ & $280 \mathrm{bp}$ \\
\hline TIMP1 U & AGATTTTAGGGGATTGGGTT & AATATCCACACTAAAAACAAAAATAACAAC & $59^{\circ} \mathrm{C}$ & $283 \mathrm{bp}$ \\
\hline MMP9 M & GAAGTTCGAAATTAGTTTGGTTAAC & TCCCGAATAACTAATATTATAAACGTA & $59.5^{\circ} \mathrm{C}$ & $110 \mathrm{bp}$ \\
\hline MMP9 U & AGTTTGAAATTAGTTTGGTTAATGT & СCТCCСAAATAACTAATATTATAAACATA & $59.5^{\circ} \mathrm{C}$ & $110 \mathrm{bp}$ \\
\hline
\end{tabular}

M: methylated, U: unmethylated, MMP: matrix metalloproteinase, TIMP: tissue inhibitor matrix metalloproteinase

Tab. 2. Detected methylation in promoter region of MMP2, TIMP2, MMP9 and TIMP1 genes.

\begin{tabular}{|c|c|c|c|c|}
\hline \multirow{2}{*}{ Gene } & \multicolumn{2}{|c|}{ AAA patients $(\mathrm{n}=43)$} & \multicolumn{2}{|c|}{ Controls $(n=34)$} \\
\hline & Methylated (n; \%) & Unmethylated (n; \%) & Methylated (n; \%) & Unmethylated (n; \%) \\
\hline$M M P 2$ & $(4 ; 9.3 \%)$ & $(39 ; 90.7 \%)$ & $(2 ; 5.9 \%)$ & $(32 ; 94.1 \%)$ \\
\hline TIMP2 & $(1 ; 2.3 \%)$ & $(42 ; 97.7 \%)$ & $(2 ; 5.9 \%)$ & $(32 ; 94.1 \%)$ \\
\hline TIMP1 & $(3 ; 7.0 \%)$ & $(40 ; 93.0 \%)$ & $(2 ; 5.9 \%)$ & $(32 ; 94.1 \%)$ \\
\hline MMP9 & $(40 ; 93.0 \%)$ & $(3 ; 7.0 \%)$ & $(31 ; 91.2 \%)$ & $(3 ; 8.8 \%)$ \\
\hline
\end{tabular}

\section{Statistical analyses}

For statistical analysis of the methylation status in the promoter region of MMP2, TIMP2, MMP9, and TIMP1 genes between the case and control groups, we used nonparametric Mann-Whitney $\mathrm{U}$ test. The difference in the methylation status of observed groups were considered to be statistically significant when $\mathrm{p} \leq 0.05$.
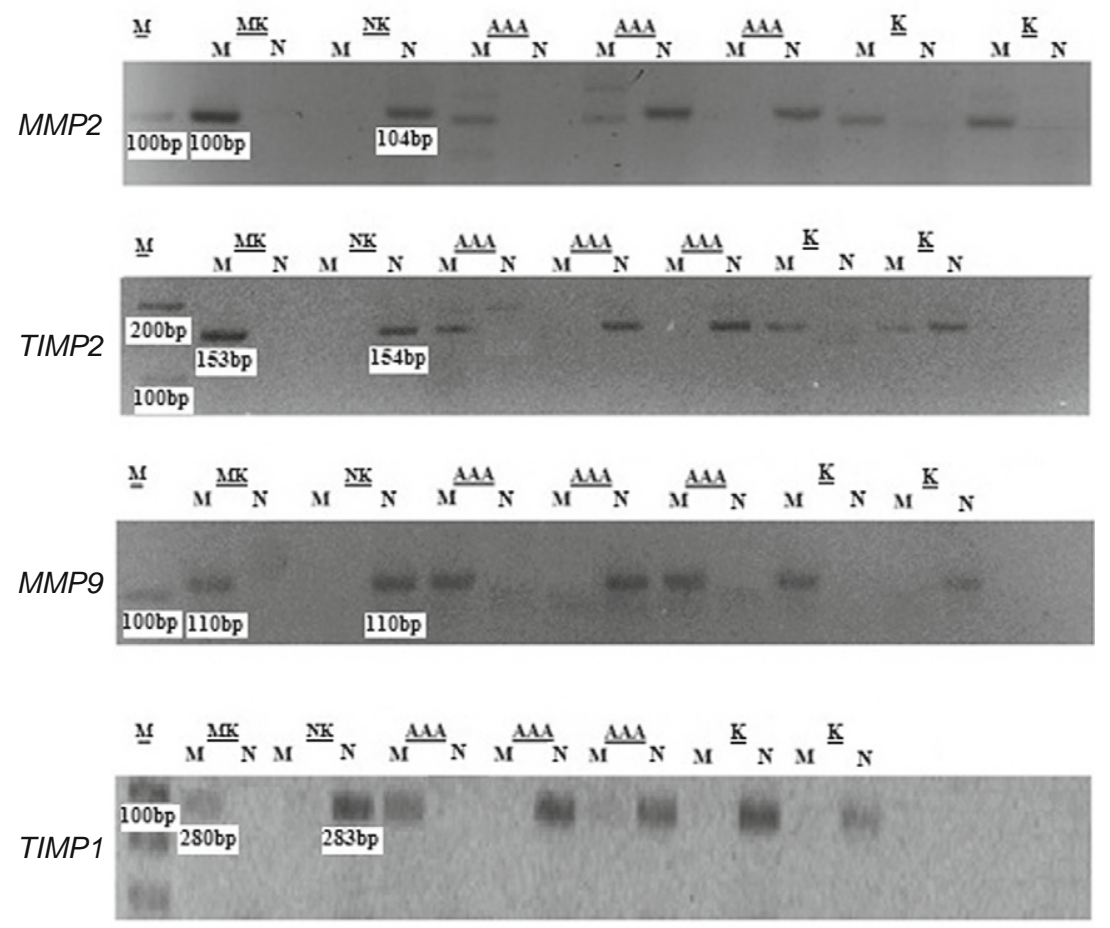

Fig. 1. Methylation status in promoter region of MMP2, TIMP2, MMP9 and TIMP1 genes. L: ladder 100bp (Thermo Fisher Scientific), MC: methylated control, UC: unmethylated control, M: methylated, U: unmethylated, AAA: abdominal aortic aneurysm samples, MMP: matrix metalloproteinase, TIMP: tissue inhibitor matrix metalloproteinase.

\section{Results}

In the examined $M M P 2$ gene, only 4 methylated cases $(9.3 \%)$ were detected within the group of AAA patients, the other examined cases were positive for the presence of unmethylated DNA sequence. It was similar in the control group, where only 2 cases $(5.9 \%)$ were methylated and the other cases were unmethylated. As to the TIMP2 gene, in the group of patients, we detected 1 methylated case $(2.3 \%)$ and 42 cases positive for the presence of unmethylated sequence. In the control group, there were 2 methylated cases (5.9\%) while 32 cases were unmethylated. As to the TIMP1 gene, in the group of patients, we observed 3 methylated cases $(7.0 \%)$ and 40 cases were positive for unmethylated sequence, while in the control group, we detected 2 methylated cases (5.9\%) and again 32 unmethylated cases. As to the last examined gene, MMP9, in patients with abdominal aortic aneurysm, we observed 40 methylated cases $(93.0 \%)$ and only 3 unmethylated cases, while in the control group, similarly 31 cases $(91.2 \%)$ were methylated and 3 cases were positive for unmethylated DNA sequence (Tab. 2). The methylation status of MMP2, TIMP2, TIMP1, and MMP9 genes detected by us correlates with the data in the human DNA methylation database (http://imethyl.iwate-megabank.org/ index.html). When comparing the methylation status in the promoter region of MMP2, TIMP2, TIMP1, and MMP9 genes by using the Mann-Whitney $U$ test ( $p>$ 
0.05), no significant differences between the case and control groups were observed. In our study, we confirmed no association of DNA methylation of the examined genes with the development of abdominal aortic aneurysm.

\section{Discussion}

DNA methylation provides a stable mechanism of gene repression that is responsible for the loss of activity of tissue-specific genes, genes on the $\mathrm{X}$ chromosome, and gene imprinting during the development, as well as in differentiated tissues of the organism $(21,22)$. DNA methylation is inherited through cell division in a symmetrical manner. It produces hemimethylated daughter strands (only one DNA strand is methylated), which serves as a template for newly synthesized DNA strands $(23,6)$. Research on atherosclerosis in cell lines and animal models has revealed that DNA methylation is an early initiator of this disease. The potential role of DNA methylation in the development of selected AAA genes has been demonstrated by several studies on methylation of AAA-related genes $(6,3)$. DNA methylation plays a role of environmental factors such as diet and lifestyle in the subsequent development and progression of AAA. Recent scientific studies have been focused on detecting differences in the methylomes of various tissue cells from a disease state by means of extensive association epigenetic analyses. Studies have shown that DNA methylation is mainly involved in specific cardiological diseases such as atherosclerosis and hypertension $(9,17)$. Presently, epigenetic effects on frequency, severity and progression of AAA are limited, with most data on AAA being inferred from studies of atherosclerosis and other inflammatory conditions. However, atherosclerosis and AAA are distinct clinical entities with overlapping risk factors and disease mechanisms (9). Using a method of sequential bisulphite analysis (WGBS) and methylation microscopic DNA analysis, Zaina et al (2014) compiled a methylation map of human atherosclerosis DNA. Significant hypermethylation has been identified at numerous sites in the genome of the atherosclerotic part of the aorta when compared with WGBS control cases. Between the case and control groups, 1,895 CpG candidate sites were methylated differently. At the same time functional expression data (qPCR) confirmed findings from 7 genes containing differently methylated regions from the same samples. The study suggests that DNA methylation in aortic tissue plays an important role in the aetiology of $\operatorname{AAA}(24,17)$. The multifactorial nature of AAA suggests the involvement of other epigenetic factors in the disease development. Krishna et al (2010) describe the role of homocysteine-mediated methylation of DNA and related epigenetic changes in AAA that appear to be important in the disease. The possible association of epigenetic risk factors and the development of AAA is still unclear. Processes that may be affected by methylation, such as chronic remodelling of ECM structures, tissue elastin media, and vascular smooth muscle cell reduction (VSMC) play an important role in the aetiology of AAA $(5,25,26)$.

In our pilot study, our team was the first to focus on the issue of abdominal aortic aneurysm in terms of epigenetic factors. The results of our study did not show a statistically significant differ- ence in the methylation status of either gene examined between case and control groups $(\mathrm{p}>0.05)$. We hypothesize that DNA methylation, as an epigenetic factor, plays an important role in the aetiology of AAA at the level of gene expression. To establish the possible association of changes in methylation status and development of AAA, further epigenetic analyses with a larger number of samples are needed. Besides, more detailed studies are needed to understand and explain the pathobiological processes affecting the origin, development, behaviour, prognosis and subsequent AAAtargeted therapy at genetic and epigenetic levels.

\section{References}

1. Pasternak J, Nikolic D, Popovic V, Vucaj-Cirilovic V. The importance of timing in surgical treatment of unruptured symptomatic aneurysm of abdominal aorta. Bratisl Med J 2012; 113 (11): 652-656.

2. Bryce Y, Rogoff P, Romanelli D, Reichle R. Endovascular repair of abdominal aortic aneurysms: vascular anatomy, device selection, procedure, and procedure- specific complications. Radiographics 2015; 35 (2): 593-615.

3. Toghill BJ, Saratzis A, Freeman PJ, Sylvius N, Bown MJ. SMYD2 promoter DNA methylation is associated with abdominal aortic aneurysm (AAA) and SMYD2 expression in vascular smooth muscle cells. Clin Epigenetics 2018; 10 (29). DOI: 10.1186/s13148-018-0460-9.

4. Kuivaniemi H, Ryer EJ, Elmore JR, Hinterseher I, Smelser DT, Tromp G. Update on abdominal aortic aneurysm research: from clinical to genetic studies. Scientifica (Cairo) 2014. DOI:10.1155/2014/564734.

5. Krishna SM, Dear AE, Norman PE, Colledge J. Genetic and epigenetic mechanisms and their possible role in abdominal aortic aneurysm. Atherosclerosis 2010; 212: 16-29.

6. Ryer EJ, Ronning KE, Erdman R, Schworer CHM, Elmore JR, Peeler TC, Nevius CHD, Lillvis JH, Garvin RP, Franklin DP, Kuivaniemi H, Tromp G. The potential role of DNA methylation in abdominal aortic aneurysms. Int J Mol Sci 2015; 16 (5): 11259-11275.

7. Bergoeing MP, Arif B, Hackmann AE, Ennis TL, Thompson RW, Curci JA. Cigarette smoking increases aortic dilatation without affecting matrix metalloproteinase- 9 and -12 expression in a modified mouse model of aneurysm formation. J Vasc Surg 2007; 45 (6): 1217-1227.

8. Kim TY, Zhong S, Fields CR, Kim JH, Robertson KD. Epigenomic profiling reveals novel and frequent targets of aberrant DNA methylation-mediated silencing in malignant glioma. Cancer Res 2006; 66 (15): 7490-7501.

9. Kim HW, Stansfield BK. Genetic and Epigenetic Regulation of Aortic Aneurysms. Biomed Res Int 2017. DOI: 10.1155/2017/7268521.

10. Ulrey CL, Liu L, Andrews LG, Tollefsbol TO. The impact of metabolism on DNA methylation. Hum Mol Genet 2005; 14 (1): 1391-147.

11. Cronenwett JL, Johnston KW. Rutherford's Vascular Surgery. Philadelphia: Elsevier Health Sciences, 2014.

12. Griffiths C, Barker J, Bleiker T, Chalmers R, Creamer D. Rook's Textbook of Dermatology. Chichester: John Wiley \& Sons, 2016.

13. Mannello F, Ligi D, Raffetto JD. Glycosaminoglycan sulodexide modulates inflammatory pathways in chronic venous disease. Int Angiol 2014; 33 (3): 236-242.

14. Opstad TB, Pettersen AA, Weiss TW, Akra S, Øvstebø R, Arnesen H, Seljeflot I. Genetic variation, gene-expression and circulating levels of 
matrix metalloproteinase-9 in patients with stable coronary artery disease. Clin Chim Acta 2012; 413: 113-120.

15. Mazuch J. Atlas vaskulárnych aneuryziem. Vydavatel'stvo P+M Turany Martin 2017; 303: 16-24.

16. Wang C, Wang Y, Yu M, Chen C, Xu L, Cao Y, Qi R. Grape-seed Polyphenols Play a Protective Role in Elastase-induced Abdominal Aortic Aneurysm in Mice. Sci Rep 2017; (1): 9402.

17. Toghill BJ, Saratzis A, Harrison SC, Verissimo AR, Mallon EB, Bown MJ. The potential role of DNA methylation in the pathogenesis of abdominal aortic aneurysm. Atherosclerosis 2015; 241 (1): 121-129.

18. Guo L, Huang C, Ji QJ. Aberrant promoter hypermethylation of p16, survivin, and retinoblastoma in gastric cancer. Bratisl Med J 2017; 118 (3): 164-168.

19. Ferrara F, Novo S, Griamudo S, Raimondi F, Meli F, Amato C, Amodeo G, Lo Presti R, Caimi G. Methylenetetrahydrofolate reductase mutation in subjects with abdominal aortic aneurysm subdivided for age. Clin Hemorheol Microcirc 2006; 34 (3): 421-426.

20. Fiebig A, Krusche P, Wolf A, Krawczak M, Timm B, Nikolaus S, Frings N, Schreiber S. Heritability of chronic venous disease. Hum Genet 2010; 127 (6): 669-674.
21. Miranda TB and Jones PA. DNA methylation: the nuts and bolts of repression. J Cell Physiol 2007; 213 (2): 384-390.

22. Haluskova J, L. Lachvac L, V. Nagy V. The investigation of GSTP1, APC and RASSF1 gene promoter hypermethylation in urine DNA of prostate-diseased patients. Bratisl Med J 2015; 116 (2): 79-82.

23. Pennings S, Allan J and Davey CS. DNA methylation, nucleosome formation and positioning. Brief Funct Genomic Proteomic 2005; 3 (4): 351-361.

24. Zaina S, Heyn H, Carmona FJ, Varol N, Sayols S, Condom E, Ramírez-Ruz J, Gomez A, Goncalves I, Moran S, Esteller M. DNA methylation map of human atherosclerosis. Circ Cardiovasc Genet 2014; 7 (5): 692-700.

25. Nozell S, Ma Z, Wilson C, Shah R, Benveniste EN. Class II major histocompatibility complex transactivator (CITA) inhibits matrix metalloproteinase-9 gene expression. J Biol Chem 2004; 279 (37): 38577-38589.

26. Wang L, Djousse L, Song Y, Akinkuonile AO, Matsumoto $\mathrm{CH}$, Manson JE, Gaziano JM, Sesso HD. Associations of Diabetes and Obesity with Risk of Abdominal Aortic Aneurysm in Men. J Obes 2017. DOI: 10.1155/2017/3521649.

27. http://imethyl.iwate-megabank.org/index.html. 